\title{
Study on Environment Planning and Development in Rural Ecological Sports Civilization Construction
}

\author{
Jianmin Xiang \\ Shangrao Normal University, Shangrao Jiangxi, 334001, China
}

\begin{abstract}
Key words: Rural ecological sports, Civilization construction, Environment planning, Environment development.
\end{abstract}

\begin{abstract}
In recent years, rural area in China has developed rapidly. In particular, the development of rural sports has greatly promoted environment planning and development in rural ecological sports civilization construction. Relevant workers should realize the importance of planning and development in work so as to better improve rural development efficiency. This paper proposes several thoughts on planning and development according to the study on environment planning and development in rural ecological sports civilization construction so as to improve environment planning and development efficiency in rural ecological sports civilization construction.
\end{abstract}

\section{Introduction}

Environment planning and development in rural ecological sports civilization construction is important for national development. In the development and research process, it is necessary to pay attention to collection of various resources and avoid the waste. Especially in the process of rural ecological sports civilization construction, researchers should attach importance to environment planning and development and accept research suggestions and opinions. Local government should give certain support, guarantee better improvement of concept education efficiency through analysis of environmental background of rural ecological sports, train peasants' sports quality, make them form good exercise habit and lay a good foundation for their development.

\section{Research object and content of environment planning and development in rural ecological sports}

\section{Research object.}

Researchers chose 50 counties and 120 villages at random from multiple prefecture-level cities in Jiangxi Province as research objects, including residents or peasants. All research objects were divided into three research age grades: 18-29, 30-44, 45-65. There was no gender restriction. Besides, the peasants with good culture foundation were selected in each village to participate in the research activity which was held in the form of questionnaire survey or lecture and exchange to strictly investigate rural ecological body-building activity and the sites. The investigation content was ecological environment of body-building sites. Effective data were acquired to make preparations for follow-up work ${ }^{[1]}$.

\section{Research content.}

During studying environment planning and development in rural ecological sports civilization construction, the general framework is as follows: firstly, analyze the background of domestic and oversea rural ecological civilization construction and actively introduce relevant concepts for some concepts and development to ensure better improvement of research efficiency; secondly, attach importance to various concepts and features of ecological civilization and sports, and mainly construct ecological civilization environment; thirdly, focus on the study on development objects of rural sports, overall analyze development status and find out the problems; fourthly, analyze rural ecological sports, classify it, and propose the relationship between rural ecological sports and entertainment, and the connotation so as to promote good health; fifthly, socialization of rural 
ecological sports education, and body-building mode; sixthly, integrate rural ecological sports resources, develop all kinds of configurations, plan and construct the environment to well improve the environment; mainly construct and plan recreational and leisure sites; seventhly, set characteristic rural ecological sports environment and make rural ecological sports operate well; eighthly, set rural ecological sports discipline and make it develop well; ninthly, take effective measures to facilitate development of rural ecological sports environment. The policies include: resource integration, good environment construction, relevant content and development mode, improvement of peasants' quality and culture and exploration of future development of rural ecological sports ${ }^{[2]}$.

\section{Problems to be solved for environment planning and development in rural ecological sports civilization construction}

\section{Key points}

the research emphases of environment planning and development in rural ecological sports civilization construction are as follows: firstly, improve the policy based on analyzing relevant concepts; secondly, improve relevant contents according to the concept and features of rural ecological sports so as to carry out moral construction for rural ecological sports; thirdly, analyze the influence factors of rural ecological sports reform, common fitness method, and fitness method of ecological sports; methods to train peasants' quality and culture; develop various functions and construct service system. Fourthly, formulate various systems, including evaluation, laws and regulations, management and education etc ${ }^{[3]}$.

\section{Difficult points}

there are many difficult points during studying environment planning and development in rural ecological sports civilization construction. Firstly, the research results should be combined on the basis of studying domestic and oversea development status; secondly, researchers find the factor influencing rural ecological sports development through studying theoretical knowledge and practical activity, i.e. lack of advanced development idea and view; secondly, it is very hard for relevant researchers to establish sound evaluation measures and supervision system for the development of rural ecological sports; finally, the following difficulties should be valued in rural ecological sports environment planning and development: firstly, sound solutions should be formulated for such problems as laggard environment construction idea, fuzzy environment construction concept and theoretical knowledge problem so as to reach the purpose of improving construction and development efficiency $^{[4]}$. Secondly, formulate sound modes and methods to ensure better improvement of peasants' physical quality. Thirdly, mainly analyze rural ecological sports and formulate measures according to the features. Fourthly, develop relevant products according to the development of rural ecological sports, formulate favorable service system and education evaluation system and guarantee netter promotion of development efficiency of rural ecological sports. Fifthly, formulate sound education system and make peasants get good humanistic quality education; ob this basis, carry out systematic ecological sports education for all peasants. Meanwhile, relevant researchers should formulate sound education and implementation schemes according to the content of rural ecological sports, innovate education methods and facilitate improvement of peasants' quality ${ }^{[5]}$.

\section{Main objectives of rural ecological sports environment planning and development}

In the research process, relevant researchers should pay attention to main research objectives, ensure better improvement of rural ecological sports environment construction efficiency and lay a good foundation for its development. The main research objectives include the following:

\section{Highlight rural ecological civilization construction}

Construction and development of rural ecological sports environment are directly related to peasants' health and concern peasants' economic benefit and long-tern development. At present, city 
environment pollution is serious and functional effect of ecological system cannot be better imp robed. Thus, relevant managers should protect rural natural environment, guide peasants to use correct training mode and lifestyle and to protect rural ecological environment, teach them theoretical knowledge of ecology and make them more respect and protect nature. Economic, political and cultural construction systems may be fused in rural ecological environment protection process to guarantee construction of rural ecological environment with certain characteristics. To some extent, the objective of sustainable development of Chinese nation can be achieved ${ }^{[6]}$.

\section{Establish correct environmental idea}

During construction and development of rural ecological sports environment, it is required to focus on establishment of environment idea, execute work with the idea of green and low carbon, shorten the distance between urban area and rural area, balance development of urban area and rural area, adjust the relationship between income and consumption, improve peasants' fitness mode and method and ensure better setting of sports development objective.

Introduce the concept of ecological civilization

During construction of rural ecological sports environment, the concept of ecological civilization should be introduced. In the process of constructing and developing ecological sports civilization environment, it is required to pay attention to energy conservation, formulate rural industrial structure with resource protection system, optimize rural consumption mode, better improve rural economic cycle efficiency, increase rural renewable resources and set favorable rural ecological sports development objective according to the introduction of ecological civilization concept ${ }^{[7]}$.

\section{Expand construction scale of rural ecological sports environment}

When relevant managers formulate sound construction mode, they should focus on expansion of rural ecological sports environment scale, publicize the significance of environment construction to peasants and make then realize the importance of ecological environment. On this basis, it is required to mainly plan the development content of rural ecological sports environment, and speed up resource integration speed. To effectively expand the scale of rural ecological scale, peasants' physical exercise situation should be observed.

\section{Basic thought on planning and development of rural ecological sports environment}

During constructing and developing rural ecological sports environment, it is required to attach importance to basic thought of construction. In order to implement General Plan of Ecological Civilization System Reform, it is required to formulate sound rural ecological civilization system according to the analysis of guiding idea on national ecological civilization construction idea and system reform, and guarantee better completion of the objective set by the state. The specific research thoughts include the following:

\section{Attach importance to the concept of resource conservation}

During environment planning and development in rural ecological sports civilization construction, it is required to introduce conservation concept, stick to resource and energy conservation and be devoted to environment protection. On this basis, rural ecological sports environment is constructed. Relevant managers should give more guidance in terms of policy and theory so as to guarantee better maintenance of national ecological environment.

Attach importance to discussion on various factors on rural ecological sports environment

\section{construction}

According to analysis of rural ecological sports civilization construction, researchers work out sound modes and methods by combining domestic and oversea development status and historical background so as to ensure better research on current situation of rural ecological sports civilization construction. Meanwhile, based on feature analysis, sound improvement measures should be formulated. 


\section{Analyze the problems in rural ecological sports civilization construction}

In the process of studying rural ecological sports civilization construction, relevant researchers should pay attention to studying relevant construction problems, guarantee better analysis of the difficulties in rural ecological sports civilization construction and propose the contradiction of environment planning and development.

\section{Solutions}

After rural ecological sports civilization construction is analyzed, several solutions are put forward. It is required to actively improve peasants' living environment, integrate various resources based on improving peasants' living quality, develop economic environment of rural ecological sports, formulate sound laws and regulations of ecological sports, highlight management system of rural ecological sports civilization construction and make it managed effectively.

\section{Various factors applicable to rural ecological sports civilization construction}

When researches execute work, they should look for the method, mode and content suitable for rural ecological environment construction. Meanwhile, it is required to pay attention to characteristics of ecological sports civilization construction, develop rural ecological sports industry, offer good sports service for peasants, guarantee better adjustment of peasants' physical exercise and entertainment mode and make their body strengthened. At the same time, sound education mode may be formulated to guide peasants to pay attention to rural ecological sports civilization construction, improve their bad habits and better participate in sports.

\section{Ecological sports promotes improvement of rural ecological environment}

Ecological environment is the source of people's life and also the root of national economic development. As rural economy develops, the quantity of household garbage becomes increasingly large, and the types of garbage are complex. Thus, peasants' living level cannot be improved effectively. Relevant managers should attach importance to improvement of rural environment, effectively create rural ecological sports atmosphere through rural ecological sports construction and guide peasants to participate in ecological environment protection. Not just can rural ecological sports environment be developed, but people's living environment can improve. Meanwhile, the foundation can be laid for better development.

\section{Ecological sports is suitable for laggard rural economic environment}

Rural sports development degree is directly related to rural economic level. When people regard sports as an entertainment event, they can participate in sports activities only when they have money or they are free. Before the reform and opening-up, the income difference between rural area and urban area was small. However after the reform and opening-up, income difference between rural area and urban area is very large, and there is a large gap in economic development. If ecological sports has no economic support, it cannot develop. Thus, relevant managers should focus on peasants' sports demand. Firstly, it is required to study peasants' exercise features and physiological load to ensure better promotion of peasants' exercise efficiency. For peasants' exercise, the sports with ornamental value and participation property is not suitable for peasants. In the process of setting ecological sports, game property should be valued so as to make sure peasants can focus on their production or living habits to develop sports events with low cost which conform to their customs, and gradually promote them. To boost development efficiency of rural ecological sports, sports events should be reasonably set, and event contents should be modified patiently.

\section{Conclusions}

The investigation and study on environment planning and development in rural ecological sports civilization construction aim at rural ecological environment and peasants' living habits. Relevant experience is surmised in the study to improve rural ecological sports civilization construction and development. Meanwhile, scientificity of project study should be valued so as to offer good reference 
for other researchers, promote rural ecological sports civilization construction efficiency and give play to the advantages of ecological environment protection to some extent.

\section{Acknowledgement}

Fund project: social science project of Jiangxi Province in "the 13th Five-year Plan"; title: study on rural ecological sports construction in Jiangxi

\section{References}

[1] Chen Yonghui, Study on ecological civilization and construction of traditional ethnic sports under view of "Wild China", Journal of Wuhan Institute of Physical Education, 2013,47(9):41-45,49.

[2] Xiao Li, Survey of rural sport consumption status in the southern region of Henan province under background of Central Plains economic region, Journal of Taiyuan Urban Vocational College, 2012(3):63-64.

[3] Fei Chenchen, Shi Zhongquan, Zhang Xiao et al., Xuanci Village: build green and livable home and create civilized and harmonious village, New Village, 2012(12):14-14.

[4] Li Hongmei, Construction of ecological consumption system, Anhui Agricultural Sciences, 2015(31):346-349,353.

[5] Liu Zeqin, Study on multi-dimensional welfare index based on fuzzy set theory, Central University of Finance and Economics, 2012.

[6] Wang Xiufu, The voice of keeping moving ahead, strengthening the city and benefiting people in mind resounds through Langfang, Hebei Water Resources, 2014(1):26-27,45.

[7] Jiang Liyi, Study on problems and countermeasures of new rural construction in Longchang County, Sichuan Agricultural University, 2014. 